\title{
Scientific Monitor
}

National Cancer Institute

\section{Source}

National Cancer Institute. Scientific Monitor. NCI Thesaurus. Code C51869.

An individual with expertise in one or more scientific disciples that can evaluate and review scientific data generated during a study. The individual reviews study records to determine that a study is being conducted in accordance with the protocol and works with the clinical research coordinator to check all data and documentation from the study. 